\title{
Open-door Laminoplasty with Preservation of Muscle Attachments of C2 and C7 for Cervical Spondylotic Myelopathy: Retrospective Study
}

\author{
Halil Ibrahim SECER ${ }^{1}$, Ferhat HARMAN², Murat Hamit AYTAR ${ }^{3}$, Serdar KAHRAMAN 4 \\ ${ }^{1}$ University of Kyrenia, Faculty of Medicine, Department of Neurosurgery, Kyrenia, Turkish Republic of North Cyprus \\ Visiting Professor at Near East University, Faculty of Medicine, Nicosia, Turkish Republic of North Cyprus \\ ${ }^{2}$ Marmara University, Faculty of Medicine, Department of Neurosurgery, Istanbul, Turkey \\ ${ }^{3}$ Acibadem University, Vocational School of Health Services, Department of First Aid and Reanimation, Istanbul, Turkey \\ ${ }^{4}$ Anadolu Medical Center, Department of Neurosurgery, Istanbul, Turkey
}

\section{ABSTRACT}

\begin{abstract}
AIM: Some restriction and complications, such as progression of kyphosis, incidence of axial neck pain and decrease of postoperative cervical range of motion are concern. We designed this retrospective clinical study to evaluate the effect of laminoplasty by preserving the muscle attachments of $\mathrm{C} 2$ and $\mathrm{C} 7$ spinous processes on range of motion (ROM), axial neck pain and cervical lordosis.
\end{abstract}

MATERIAL and METHODS: Twenty-seven cases with cervical spondylotic myelopathy underwent open-door laminoplasty with the protection of muscle attachments to the C2 and C7 spinous process and laminae between 2007 and 2013. At the end of the followup, cases were evaluated with preoperative and postoperative modified Japanese Orthopedic Association (mJOA) scores, recovery rate, $\mathrm{ROM}$, lordosis angle and visual analogue scale (VAS). Also, patients were divided into two groups and evaluated according to the magnetic resonance imaging (MRI) findings, with or without T2 signal change.

RESULTS: The mean age of the patients was 66 years. The mean follow-up duration was 25 months. The postoperative mJOA scores were significantly higher than the preoperative mJOA scores $(p<0.001)$. The recovery rate was $57.4 \%$. Although the postoperative VAS score was higher than the preoperative VAS score and the mean postoperative ROM was lower than the preoperative ROM there was no significant difference between preoperative and postoperative VAS score and ROM ( $p>0.05$ ). The postoperative lordosis angle was significantly lower than the preoperative lordosis angle $(p<0.05)$. There were no significant differences regarding the postoperative lordosis angle, ROM and mJOA scores with or without T2 signal change on MRI.

CONCLUSION: Protection of the anatomic structures around the cervical spine such as the muscles and ligaments provides us better results regarding ROM and cervical axial pain.

KEYWORDS: Laminoplasty, Cervical spondylotic myelopathy, Range of motion, Lordosis

\section{INTRODUCTION}

$\mathrm{L}$ aminoplasty is a good alternative to laminectomy for the treatment of cervical spinal stenosis with/ Iwithout myelopathy $(3,18,20,21,36-38)$. The expansive laminoplasty technique was first described by Oyama et al. (26). After that, the unilateral open-door laminoplasty technique was modified and developed by Hirabayashi and the double-door laminoplasty technique by Kurokawa $(5,20)$. Although cervical laminoplasty is a motion- preserving procedure, several studies have reported some complications and problems such as axial neck pain, kyphotic deformity, and reduction of cervical range of motion (ROM) on long-term follow-up $(6,8,20)$. 
In recent procedures, preservation of muscle attachments is a new and important development for the laminoplasty technique to reduce axial neck pain and restriction of cervical ROM. They all reach the consensus that protection of muscle attachments positively contributed to the reduction of pain and $\operatorname{ROM}(17,19,30-35,38)$.

Despite wide clinical experience about laminoplasty, the efficacy of and best procedure for laminoplasty remains unclear. We designed this retrospective study to evaluate the patients who underwent open-door laminoplasty with preservation of muscle attachments of $\mathrm{C} 2$ and $\mathrm{C} 7$ spinous processes for cervical spondylotic myelopathy and compared the preoperative and postoperative clinical and radiological features.

\section{MATERIAL and METHODS}

\section{Patient Demographics}

There were 27 consecutive patients with cervical spondylotic myelopathy. All the patients underwent the open-door laminoplasty procedure by two experienced surgeons between December 2007 and October 2013. There were 20 males (74\%) and 7 females (26\%). The mean age at the time of surgery was 66 years (range 45-83 years). The mean duration of the symptoms before the surgery was 14 months (range 3-42 months). The mean follow-up duration was 25 months (range 6-45 months).

At the end of the follow-up period, each patient's status was evaluated with preoperative and postoperative modified Japanese Orthopedic Association (mJOA) scores, recovery rate, ROM, lordosis angle and visual analogue scale (VAS). Also, the patients were divided into two groups and evaluated according to the magnetic resonance imaging (MRI) findings, with or without T2 signal change. There were 12 patients who had a T2 signal change in the spinal cord on MRI scan (T2-MRI (+) group) and 15 patients who did not have a signal change in the spinal cord on MRI scan (T2-MRI (-) group).

\section{Surgical Procedures}

The head was fixed with a Mayfield frame and the patient was rotated to the prone position. A posterior midline $\mathrm{C} 2-\mathrm{C} 7$ skin incision was made. The paravertebral muscles were dissected from the spinous processes and lamina to the facet joints, but facet capsules were preserved to avoid fusion. Muscles attached to the $\mathrm{C} 2$ and $\mathrm{C} 7$ spinous process and laminae were all protected. The supraspinous and interspinous ligaments were strictly preserved. The patient's more painful or neurologically affected side was chosen as the laminotomy side. The operating microscope was routinely used during all laminoplasty procedures. A triangle-shaped bone gutter at the medial margin of the facet joints was made at the contralateral side with a high-speed drill. The laminotomy was performed with a high-speed drill or a Number 1 Kerrison rongeur at one side. The lamina and ligamentum flavum were elevated from the open side and hinged on the other side, which decompressed and relieved the spinal cord. A titanium laminoplasty plate was used to maintain patency of the open-door laminoplasty (NewBridge laminoplasty fixation systems, Orthofix, Lewisville, USA). Foraminotomy was performed in cases of myeloradiculopathy. C5 foraminotomy was not performed routinely. Postoperatively, the patients used a soft cervical collar for 2 weeks.

\section{Neurological Assessment}

Postoperative results were evaluated by using the mJOA score (14). Using a formula, the degree of postoperative neurological recovery was calculated as follows (5).

Recovery rate $(\%)=$ (postoperative $\mathrm{mJOA}$ score-preoperative $\mathrm{mJOA}$ score)/(full mJOA score [18]-preoperative mJOA score) $\mathrm{x} 100$.

\section{Radiological Assessments}

Preoperative and postoperative ROM, and the preoperative and postoperative lordosis angle were measured on the lateral cervical spine $\mathrm{x}$-rays according to the relevant literature. The angle of cervical lordosis angle was measured between a line parallel to the posterior surface of the body of the $\mathrm{C} 2$ and a line parallel to the posterior surface of the body of C7 (13).

\section{Statistical Analyses}

Statistical analyses were performed using the IBM SPSS for Windows Version 21.0 statistical package. Continuous variables were presented as mean \pm standard [minimum - maximum]. Categorical variables were summarized as frequencies and percentages. Normality of the continuous variables was evaluated by Shapiro-Wilk test. Differences between the two groups according to continuous variables were determined by Mann-Whitney $U$ test. Differences between preoperative and postoperative values were evaluated by the Wilcoxon signed rank test. A p value less than 0.05 was considered as significant.

\section{RESULTS}

In all patients, the mean operative time was 105 minutes (range 90-150 minutes), and the mean estimated blood loss was $355 \mathrm{ml}$ (range 200-600 ml). The mean age was $66.8 \pm 8.2$ years (range $45-83$ years). Laminoplasty was started from the C3 level in 18 cases (66\%). Laminoplasty was performed on 4 levels in 13 cases, 3 levels in 12 cases and 2 levels in only 2 cases. There were T2 signal changes in 12 cases (Table I).

The mean preoperative mJOA scores were $12.2 \pm 2.4$ and postoperative mJOA scores were $15.0 \pm 2.5$. The postoperative mJOA scores were significantly higher than the preoperative mJOA scores $(p<0.001)$. The recovery rate was $57.4 \%$ (Table II).

The mean preoperative VAS score was $5.6 \pm 1.4$ and the postoperative VAS score was 6.2 \pm 1.9 . Although the postoperative VAS score was higher than the preoperative VAS score, there was no statistically significant difference between them ( $p>0.05$ ) (Table II).

The postoperative ROM decreased in the 22 cases, did not change in 2 cases and increased in 3 cases when compared with the preoperative ROM. The mean preoperative ROM 
was $35.3 \pm 5.3$ (range 22-43) degrees and postoperative ROM was 34.0 \pm 6.4 (range 20-52) degrees. Although the mean postoperative ROM was lower than the preoperative ROM,

Table I: Patient Characteristics

\begin{tabular}{lcc}
\hline & & \multicolumn{1}{c}{ Mean \pm SD } \\
\hline Age & & $66.8 \pm 8.2$ years \\
\hline Duration of Symptoms & & $14.0 \pm 9.3$ months \\
\hline Recovery rate & & $57.4 \pm 28.3$ \\
\hline Duration of Follow-up & & $25.0 \pm 10.7$ months \\
\hline & & Frequency \\
\hline \multirow{2}{*}{ MRI } & - & 15 \\
\hline \multirow{3}{*}{ Level } & T2 & 12 \\
\cline { 2 - 3 } & $2(\mathrm{C} 4-\mathrm{C} 5)$ & 1 \\
\cline { 2 - 3 } & $2(\mathrm{C} 5-\mathrm{C} 6)$ & 1 \\
\cline { 2 - 3 } & $3(\mathrm{C} 3-\mathrm{C} 5)$ & 5 \\
\cline { 2 - 3 } & $3(\mathrm{C} 4-\mathrm{C} 6)$ & 7 \\
\cline { 2 - 3 } & $4(\mathrm{C} 3-\mathrm{C} 6)$ & 13 \\
\hline \multirow{3}{*}{ Number of Level } & 2 & 2 \\
\cline { 2 - 3 } & 3 & 12 \\
\cline { 2 - 3 } C5 Palsy & 4 & 13 \\
\hline
\end{tabular}

there was no statistically difference between them $(p>0.05)$ (Table II).

The preoperative cervical lordosis angle ranged from -10 to 37 degrees and cases with cervical kyphosis higher than -10 degrees were not operated on with this techniques. Postoperative cervical lordosis angles ranged from -15 to 30 degrees and decreased in 16 cases, did not change in 8 cases and increased in 3 cases when compared with the preoperative lordosis angle. The mean preoperative lordosis angle was $14.1^{\circ} \pm 13.5^{\circ}$ (range $-10^{\circ} \pm 37^{\circ}$ ) and postoperative lordosis angle was $12.6^{\circ} \pm 13.5^{\circ}\left(\right.$ range $\left.-15^{\circ} \pm 30^{\circ}\right)$. The postoperative lordosis angle was significantly lower than the preoperative lordosis angle $(p<0.05)$ (Table II).

While evaluating the recovery rate according to the T2 signal change in the spinal cord on MRI scan, the mean recovery rate was $73.6 \pm 25.2$ in the T2-MRI (+) group and $37.1 \pm 16.8$ in the T2-MRI (-) group. The recovery rate of the T2-MRI (+) group was significantly higher than the T2-MRI (-) group $(p<0.05)$. There were no significant differences regarding the postoperative lordosis angle, ROM and mJOA scores between these two groups (Table III).

Temporary C5 nerve root palsy had occurred on the hinged side of three patients (11.1\%). All patients with C5 nerve root palsy were completely recovered within 3 months. In one patient, deep surgical site infection developed. Staphylococcus aureus was isolated from the culture material and the condition cured within six weeks using vancomycin (Kocak Farma Pharmacy and Chemical Industry, Istanbul, Turkey) treatment. One patient had a C6 screw pull-out at the second month of operation and was revised surgically. While elevating the lamina, the hinged side was broken in 2 patients and fixed with a miniplate/screw system.

Table II: The Results and Statistical Analysis of Lordosis and ROM Degrees, JOA and VAS Scores

\begin{tabular}{lccc}
\hline & Preoperative & Postoperative & p \\
\hline Mean \pm SD & Mean \pm SD & \\
\hline mJOA score & $14.1 \pm 13.5$ & $12.6 \pm 13.5$ & 0.005 \\
\hline ROM & $12.2 \pm 2.4$ & $15.0 \pm 2.5$ & $<0.001$ \\
\hline VAS & $35.3 \pm 5.3$ & $34.0 \pm 6.4$ & 0.216 \\
\hline
\end{tabular}

Table III: Analyzing the Effect of MRI T2 Signal Change in the Spinal Cord on Recovery Rate, mJOA Score, Lordosis and ROM Degrees

\begin{tabular}{lcll}
\hline & MRI (-) & MRI (T2+) & p \\
\hline Mean \pm SD & Mean \pm SD & \\
\hline$\Delta$ Locovery rate & $73.6 \pm 25.2$ & $37.1 \pm 16.8$ & 0.001 \\
\hline$\Delta$ mJOA score & $3.5 \pm 3.8$ & $-0.9 \pm 8.1$ & 0.139 \\
\hline$\Delta$ ROM & $-3.0 \pm 1.4$ & $-2.7 \pm 1.1$ & 0.755 \\
\hline
\end{tabular}




\section{- DISCUSSION}

During the past decades, laminoplasty has become a good treatment choice for many surgeons in cases of cervical spondylotic myelopathy after the development of the open-door laminoplasty technique. There are two different mechanisms ensuring decompression of the spinal cord with the laminoplasty method. Firstly, direct local decompression of the posterior elements decreases the posterior pressure on the spinal cord. Secondly, the dorsal shift of the spinal cord moves it away from the anterior compressing factors such as osteophytes, ossified-hypertrophic ligaments and protruding discs, obtaining a total decompression effect (7).

Many modifications such as bone grafts, hydroxyapatite or other ceramic materials, allograft and titanium plates, titanium miniplates and screws have been developed to prevent this complication $(2,7,20,21,39)$. We have preferred titanium miniplates (Blackstone Medical Inc, USA). We achieved good results with this technique. While elevating the lamina, the hinged side was broken in only 2 patients and fixed with a miniplate/screw system. Just one patient had a C6 screw pull-out at the second month of operation and was revised surgically.

In the earliest Hirabayashi report, open-door laminoplasty was performed in 40 patients with multilevel cervical spondylotic myelopathy and most of the patients had good results. The recovery rate was $66 \%$ with the JOA scale score in this series. Many other surgeons reported similar results with JOA scores and neurological recovery rates after various techniques of laminoplasty. They reported the improvement to be stable for more than 10 years in most patients $(1,22,29)$. We found that the postoperative mJOA scores were significantly higher than the preoperative mJOA scores and the recovery rate was $57.4 \%$ in our study which is similar to the previous literature.

Although cervical laminoplasty is an effective decompressing and motion-preserving procedure, several studies have reported some complications and problems such as axial neck pain, kyphotic deformity, and reduction of cervical ROM on long-term follow-up $(6,8,20)$. In this study, although the postoperative lordosis degree was statistically lower than the preoperative lordosis degree, there was no statistically significant difference between the postoperative ROM and the preoperative ROM. Kang et al. retrospectively evaluated 20 laminoplasty patients with their preoperative and postoperative ROM and they determined factors (JOA score, duration of symptoms, disease entity, age and sex) associated with cervical ROM. They found cervical ROM was reduced after laminoplasty and there was no correlative factor that was associated with a reduction in cervical ROM (16). Duetzmann et al. presented a wide literature review about 103 laminoplasty series and noted that in all series a mean $47.3 \%$ loss of ROM was reported (2). We found a decrease in neck flexibility after the laminoplasty procedure, but there was no statistically significant difference.

Kyphosis can develop after cervical laminoplasty in the straight or lordotic cervical spine. Iwasaki et al. reported as $8 \%$ progressive kyphotic deformity after cervical laminoplasty, but no neurological deterioration (11). Some authors presented that detachment of cervical muscles, especially the semispinalis cervicis muscle attached to the C2 spina, were associated with postoperative kyphosis $(12,20)$. No detachment and preservation of the deep extensor muscles to the $\mathrm{C} 2$ spinous process was correlated with postoperative changes in cervical kyphotic deterioration $(2,12,32-34,38)$. Duetzmann et al. reviewed a total of 103 studies from MEDLINE. They showed that only 21 studies had statistical comparisons between preoperative and postoperative C2C7 angles. Moreover, $28.8 \%$ of these studies reported had stable alignment, $45.0 \%$ had worse kyphosis, and $26.3 \%$ had increased lordotic curvature. They emphasized that understanding the muscle-ligament complex is important for better surgical results of cervical aligment. In our cases, the muscles attached to the $\mathrm{C} 2$ and $\mathrm{C} 7$ spinous process and the supraspinous and interspinous ligaments were strictly preserved peroperatively (2).

Hardacker et al. and Scheer et al. evaluated the cervical sagittal parameters and they found cervical lordosis angle was not occurred evident symptom until that angle decreased to -9.6 degrees $(4,28)$. We did not operate on patients with a lordosis angle lower than -10 degrees. However, in three cases, the postoperative lordosis angle increased to over -10 degrees when compared with the preoperative lordosis angle ( -8 to $-12,-5$ to -12 , and -10 to -15 degree). In one case, the preoperative lordosis angle increased from -10 to +16 degrees. In this study, the postoperative lordosis angle was significantly lower than the preoperative lordosis angle. Protection of the C2 and C7 spinous-attached muscles during the surgery and not operating on patients with cervical lordosis lower than -10 degrees is important for maintenance of cervical lordosis after laminoplasty. Even if ROM and axial neck pain had negative effects, it did not cause a statistically significant change.

Many authors have reported axial neck pain in $27 \%-90 \%$ of patients after laminoplasty for cervical spondylotic myelopathy $(8,10,23)$. Causes of axial pain are still uncertain. Many studies have shown that preservation of $\mathrm{C} 2$ and $\mathrm{C} 7$ spinous processes reduced the frequency of postoperative axial neck pain $(9,10,25,27,33,34,38)$. In the present study, the mean preoperative VAS score for axial neck pain was $5.6 \pm 1.4$ and the postoperative VAS score was $6.2 \pm 1.9$ at the end of the follow-up period. Although the postoperative VAS score was higher than the preoperative VAS score, there was no statistically significant difference between them ( $p>0.05$ ). One reason for the relative infrequency of axial neck pain among our patients was the preservation of the semispinalis muscle insertion into $\mathrm{C} 2$, and the paravertebral muscles at the C7. Another factor influencing axial neck pain is the use of a cervical soft collar in the early postoperative period. This should be shortened. In the present study, the brace therapy period was limited to 2 weeks, and active sitting, standing, and ambulation were started on the postoperative first day.

The C5 nerve root is the most commonly affected nerve root after open-door laminoplasty and nerve injury usually results in motor weakness $(6,15)$. The tethering of the nerve roots with posterior migration of the spinal cord may cause this 
problem. Patients with ossified posterior longitudinal ligament (OPLL) also have a higher risk of C5 nerve palsy (36). Gentle elevation of the lamina may be effective for the prevention of this complication (15). In our series, C5 nerve palsy occurred in 3 patients $(11.1 \%)$ in the early postoperative period and all of them recovered within a few months. All of them were operated on four levels (C3-C6) and two had MRI T2 changes preoperatively.

Spinal cord signal changes on MRI of cervical spondylotic myelopathy patients have been correlated with preoperative and postoperative neurological condition and JOA scores. Sun et al. showed that T2-WI hyperintense MRI changes were present in approximately $80.7 \%$ of all patients and MRI parameters were significant predictors of surgical outcome (31). Nouri et al. prospectively evaluated 102 patient's MRI parameters and mJOA scores. They showed that MRI changes have a significant role in predicting the surgical outcome (24). Similarly in our study, we also evaluated T2-WI changes on MRI. Recovery rate of the T2-MRI (-) group was significantly higher than the T2-MRI (+) group. Change of lordosis angle, mJOA scores and ROM was not evident postoperatively between two groups.

\section{CONCLUSION}

Laminoplasty has become an effective treatment method for many cases of cervical spondylotic myelopathy after the development of the open-door laminoplasty technique. The patients with preoperative MRI changes in the spinal cord have worse post-laminoplasty outcome and neurological condition. Protection of the anatomical structures around the cervical spine such as the muscles attached to the $\mathrm{C} 2$ and $\mathrm{C} 7$ spinous process, and the supraspinous and interspinous ligaments provides better results regarding ROM and cervical axial pain.

\section{- REFERENCES}

1. Chiba K, Ogawa $Y$, Ishii $K$, Takaishi H, Nakamura M, Maruiwa $H$, Matsumoto $M$, Toyama $Y$ : Long-term results of expansive open-door laminoplasty for cervical myelopathy-Average 14-year follow-up study. Spine 31: 2998-3005, 2006

2. Duetzmann S, Cole T, Ratliff JK: Cervical laminoplasty developments and trends, 2003-2013: A systematic review. J Neurosurg Spine 23(1): 24-34, 2015

3. Hale JJ, Gruson KI, Spivak JM: Laminoplasty: A review of its role in compressive cervical myelopathy. Spine J 6 Suppl 6: 289-298, 2006

4. Hardacker JW, Shuford RF, Capicotto PN, Pryor PW: Radiographic standing cervical segmental alignment in adult volunteers without neck symptoms. Spine 22(13): 1472-1480, 1997

5. Hirabayashi K, Satomi K: Operative procedure and results of expansive open-door laminoplasty. Spine 13(7): 870-876, 1988

6. Hirabayashi K, Toyama Y, Chiba K: Expansive laminoplasty for myelopathy in ossification of the longitudinal ligament. Clin Orthop Relat Res 359: 35-48, 1999
7. Hirabayashi K, Watanabe K, Wakano K, Suzuki N, Satomi K, Ishii Y: Expansive open-door laminoplasty for cervical spinal stenotic myelopathy. Spine 8(7): 693-699, 1983

8. Hosono N, Sakaura H, Mukai Y, Fujii R, Yoshikawa H: C3-6 laminoplasty takes over C3-7 laminoplasty with significantly lower incidence of axial neck pain. Eur Spine J 15:1375-1379, 2006

9. Hosono N, Sakaura H, Mukai Y, Ishii T, Yoshikawa H: En-bloc laminoplasty without dissection of paraspinal muscles. J Neurosurg Spine 3: 29-33, 2005

10. Hosono N, Yonenobu K, Ono K: Neck and shoulder pain after laminoplasty. A noticeable complication. Spine 21(17):19691973, 1996

11. Iwasaki M, Kawaguchi Y, Kimura T, Yonenobu K: Long-term results of expansive laminoplasty for ossification of the posterior longitudinal ligament of the cervical spine: More than 10 years follow up. J Neurosurg 96 Suppl 2: 180-189, 2002

12. Izuka H, Shimizu T, Tateno K, Toda N, Edakuni $H$, Shimada $H$, Takagishi K: Extensor musculature of the cervical spine after laminoplasty: Morphologic evaluation by coronal view of the magnetic resonance image. Spine 26: 2220-2226, 2001

13. Jackson R: The Cervical Syndrome, $2^{\text {nd }}$ ed. Springfield, IL: Charles C. Thomas, 1958:174

14. Japanese Orthopedic Association. Scoring system for cervical myelopathy. J Jpn Orthop Assoc 68: 490-503, 1994

15. Kaminsky SB, Clark CR, Traynelis VC: Operative treatment of cervical spondylotic myelopathy and radiculopathy. A comparison of laminectomy and laminoplasty at five year average follow-up. lowa Orthop J 24: 95-105, 2004

16. Kang SH, Rhim SC, Roh SW, Jeon SR, Baek HC: Postlaminoplasty cervical range of motion: Early results. J Neurosurg Spine 6(5): 386-390, 2007

17. Kim P, Murata H, Kurokawa R, Takaishi Y, Asakuno K, Kawamoto T: Myoarchitectonic spinolaminoplasty: Efficacy in reconstituting the cervical musculature and preserving biomechanical function. J Neurosurg Spine 7: 293-304, 2007

18. Kimura A, Seichi A, Inoue $H$, Hoshino Y: Long-term results of double-door laminoplasty using hydroxyapatite spacers in patients with compressive cervical myelopathy. Eur Spine J 20: 1560-1566, 2011

19. Kotani $Y$, Abumi K, Ito $M$, Sudo $H$, Takahata $M$, Ohshima $S$, Hojo Y, Minami A: Minimum 2-year outcome of cervical laminoplasty with deep extensor muscle-preserving approach: Impact on cervical spine function and quality of life. Eur Spine J 18(5): 663-671, 2009

20. Kurokawa R, Kim P: Cervical laminoplasty: The history and the future. Neurol Med Chir (Tokyo) 55(7): 529-539, 2015

21. Lin S, Zhou F, Sun Y, Chen Z, Zhang F, Pan S: The severity of operative invasion to the posterior muscular-ligament complex influences cervical sagittal balance after open-door laminoplasty. Eur Spine J 24(1): 127-135, 2015

22. Machino M, Yukawa $Y$, Hida T, Ito $K$, Nakashima $H$, Kanbara S, Morita D, Kato F: Modified double-door laminoplasty in managing multilevel cervical spondylotic myelopathy: Surgical outcome in 520 patients and technique description. J Spinal Disord Tech 26: 135-140, 2013 
23. Nakano N, Nakano T, Nakano K: Comparison of the results of laminectomy and open-door laminoplasty for cervical spondylotic myeloradiculopathy and ossifcation of the posterior longitudinal ligament. Spine 13: 792-794, 1988

24. Nouri A, Tetreault L, Zamorano JJ, Dalzell K, Davis AM, Mikulis $D$, Yee A, Fehlings MG: Role of magnetic resonance imaging in predicting surgical outcome in patients with cervical spondylotic myelopathy. Spine 40(3): 171-178, 2015

25. Ono A, Tonosaki Y, Yokoyama T, Aburakawa S, Takeuchi K,Numasawa T, Wada K, Kachi T, Toh S: Surgical anatomy of the nuchal muscles in the posterior cervicothoracic junction: Signifcance of the preservation of the $\mathrm{C} 7$ spinous process in cervical laminoplasty. Spine 33: E349-E354, 2008

26. Oyama M, Hattori S, Moriwaki N: A new method of cervical laminoplasty. Centr Jpn J Orthop Traumatic Surg 16: 792794, 1973

27. Sakaura H, Hosono N, Mukai Y, Iwasaki M, Yoshikawa $H$ : Medium-term outcomes of C3-6 laminoplasty for cervical myelopathy: A prospective study with a minimum 5-year follow-up. Eur Spine J 20: 928-933, 2011

28. Scheer JK, Tang JA, Smith JS, Acosta FL Jr, Protopsaltis TS, Blondel B, Bess S, Shaffrey Cl, Deviren V, Lafage V, Schwab F, Ames CP; International Spine Study Group: Cervical spine alignment, sagittal deformity, and clinical implications: A review. J Neurosurg Spine 19(2): 141-159, 2013

29. Seichi A, Takeshita K, Ohishi I, Kawaguchi H, Akune T, Anamizu Y, Kitagawa T, Nakamura K: Long-term results of double-door laminoplasty for cervical stenotic myelopathy. Spine 26: 479-487, 2001

30. Shiraishi T: A new technique for exposure of the cervical spine laminae. Technical note. J Neurosurg 96: 122-126, 2002

31. Sun Y, Zhang F, Wang S, Zhang L, Pan S, Yu M, Qiu S: Open door expansive laminoplasty and postoperative axial symptoms: A comparative study between two different procedures. Evid Based Spine Care J 1(3): 27-33, 2010
32. Takeuchi K, Yokoyama T, Ono A, Numasawa T, Wada K, Kumagai G, Ito J, Ueyama K, Toh S: Cervical range of motion and alignment after laminoplasty preserving or reattaching the semispinalis cervicis inserted into axis. J Spinal Disord Tech 20: 571-576, 2007

33. Takeuchi K, Yokoyama T, Aburakawa S, Saito A, Numasawa T, Iwasaki T, Itabashi T, Okada A, Ito J, Ueyama K, Toh S: Axial symptoms after cervical laminoplasty with C3 laminectomy compared with conventional C3-C7 laminoplasty: A modifed laminoplasty preserving the semispinalis cervicis inserted into axis. Spine 30: 2544-2549, 2005

34. Takeuchi K, Yokoyama T, Ono A, Numasawa T, Wada K, Itabashi T, Toh S: Limitation of activities of daily living accompanying reduced neck mobility after laminoplasty preserving or reattaching the semispinalis cervicis into axis. Eur Spine J 17(3): 415-420, 2008

35. Takeuchi T, Shono Y: Importance of preserving the $\mathrm{C} 7$ spinous process and attached nuchal ligament in Frenchdoor laminoplasty to reduce postoperative axial symptoms. Eur Spine J 16(9): 1417-1422, 2007

36. Tetreault L, Ibrahim A, Côté P, Singh A, Fehlings MG: A systemic review of clinical and surgical predictors of complications following surgery for degenerative cervical myelopathy. J Neurosurg Spine 25:1-23, 2015

37. Tomita K, Kawahara N, Toribatake Y, Heller JG: Expansive midline T-saw laminoplasty (modified spinous processsplitting) for the management of cervical myelopathy. Spine 23: 32-37, 1998

38. Tumturk A, Kuçuk A, Menku A, Koc RK: En bloc cervical laminoplasty with preserving posterior structure and arcocristectomy in cervical spondylotic myelopathy. Turk Neurosurg 27(5):790-796, 2016

39. Yeh KT, Yu TC, Chen IH, Peng CH, Liu KL, Lee RP, Wu WT: Expansive open-door laminoplasty secured with titanium miniplates is a good surgical method for multiple-level cervical stenosis. J Orthop Surg Res 9:49, 2014 